\title{
Predictors of temporary epicardial pacing wires use after valve surgery
}

\author{
Nizar R AlWaqfi ${ }^{*}$, Khaled S Ibrahim', Yousef S Khader ${ }^{2}$ and Ahmad Abu Baker ${ }^{3}$
}

\begin{abstract}
Background: Although temporary cardiac pacing is infrequently needed, temporary epicardial pacing wires are routinely inserted after valve surgery. As they are associated with infrequent, but life threatening complications, and the decreased need for postoperative pacing in a group of low risk patients; this study aims to identify the predictors of temporary cardiac pacing after valve surgery.

Methods: A retrospective analysis of data collected prospectively on 400 consecutive valve surgery patients between May 2002 and December 2012 was performed. Patients were grouped according to avoidance or insertion of temporary pacing wires, and were further subdivided according to temporary cardiac pacing need. Multiple logistic regression was used to determine the predictors of temporary cardiac pacing.

Results: 170 (42.5\%) patients did not have insertion of temporary pacing wires and none of them needed temporary pacing. 230 (57.5\%) patients had insertion of temporary pacing wires and among these, only 55 (23.9\%) required temporary pacing who were compared with the remaining 175 (76.1\%) patients in the main analysis. The determinants of temporary cardiac pacing (adjusted odds ratios; 95\% confidence interval) were as follows: increased age $(1.1 ; 1.1,1.3, p=0.002)$, New York Heart Association class III- IV $(5.6 ; 1.6,20.2, p=0.008)$, pulmonary artery pressure $\geq 50 \mathrm{mmHg}(22.0 ; 3.4,142.7, p=0.01)$, digoxin use $(8.0 ; 1.3,48.8, p=0.024)$, multiple valve surgery (13.5; $1.5,124.0, p=0.021$ ), aorta cross clamp time $\geq 60$ minutes $(7.8 ; 1.6,37.2, p=0.010)$, and valve annulus calcification (7.9; 2.0, 31.7, $p=0.003)$.

Conclusion: Although limited by sample size, the present results suggest that routine use of temporary epicardial pacing wires after valve surgery is only necessary for high risk patients. Preoperative identification and aggressive management of predictors of temporary cardiac pacing and the possible modulation of intraoperative techniques can decrease the need of temporary cardiac pacing. Prospective randomized controlled studies on a larger number of patients are necessary to draw solid conclusions regarding the selective use of temporary epicardial pacing wires in valve surgery.
\end{abstract}

Keywords: Pacing heart, Temporary pacing, Heart valves

\section{Background}

Starting 1960s, temporary epicardial pacing wires (PWs) were routinely placed in all cardiac operations for therapeutic as well as diagnostic purposes $[1,2]$. They remain in place anywhere from 24 hours to several days postoperatively and are used to maintain heart rate and rhythm which are necessary to optimize haemodynamics [3] and to suppress both atrial and ventricular tachyarrhythmias

\footnotetext{
* Correspondence: nizarwaqfi@hotmail.com

'Department of General Surgery, Jordan University of Science and Technology and King Abdullah University Hospital, Princess Muna Heart Center, Floor 8 C, Po Box 630001, Irbid 22110, Jordan

Full list of author information is available at the end of the article
}

[4]. The use of PWs is associated with increased resource utilization and infrequent, but life threatening complications including hemorrhage, cardiac tamponade, serious arrhythmias, and death. Also the retention of PWs after cardiac surgery is not necessarily safe and may cause serious complications [5-11].

The available data supports the use of PWs for selected cases after coronary artery bypass grafting (CABG) surgery $[5,6]$. However, PWs are routinely inserted after valve and congenital heart surgeries promoted by historical evidence of increased need for temporary cardiac pacing (TCP) in such surgeries [12-14]. Recent limited

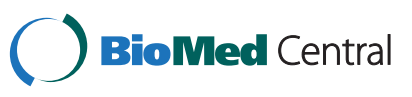


publications suggest a trend towards selective use $[15,16]$. Ferrari et al. [15] reported TCP in $17 \%$ of their valve surgery cases and Gupta et al. [16] in 30\% of their congenital heart surgery cases.

The aim of this study was to determine the predictors of TCP in valve surgery with the potential to regulate PWs insertion at our center.

\section{Methods}

\section{Patients}

This study is a retrospective review of the clinical, operative, and outcome data that is part of the prospectively recorded cardiac intensive care unit (CICU) database. We excluded patients who underwent redo valve surgery due to their small number and patients with preoperative high degree atrioventricular block (AVB). A total of 400 patients, 18 years or older underwent valve surgery at King Abdullah University Hospital (KAUH), Jordan between May, 2002 and December, 2012, was included in the analysis.

Lately, it is our clinical practice, and upon surgeon's discretion based on patient's individual characteristics to selectively insert PWs in valve surgery patients.

According to insertion or avoidance of PWs, two groups of patients were identified: group 1; did not have PWs inserted and never needed to be paced and group 2; had PWs inserted. Group 2 was subdivided into patients who needed TCP and those who did not need TCP. This study was approved by the ethical committee at KAUH.

\section{Variables}

The need for postoperative TCP (if patients were paced at the time of chest closure or at any time before hospital discharge) was the outcome variable of interest. We identified the demographic, clinical, preoperative (including drugs directly affecting the conduction system), and intraoperative variables (including type of valve surgery) as potential predictors of TCP (Table 1). Preoperative arrhythmias were defined as atrial fibrillation (AF), low grade AVB, or a bundle branch block diagnosed by electrocardiogram (ECG). Type of valve surgery was subdivided into; mitral valve, aortic valve, multiple valve (double or triple), and valve with CABG surgeries. There were no cases of only-tricuspid valve surgery, but part of a combined procedure.

\section{Operative technique}

All patients had median sternotomy. In mitral valve surgery, cardiopulmonary bypass (CPB) was established between the ascending aorta and bicaval venous cannulation. Mitral valve was approached through a conventional left lateral atriotomy. Perfusion was maintained at 2.0 to $2.4 \mathrm{~L} / \mathrm{min} / \mathrm{m}^{2}$, and systemic perfusion pressure was kept at $60-80 \mathrm{mmHg}$. Myocardial protection was achieved by hypokalemic cold crystalloid antegrade cardioplegia $(10-12 \mathrm{ml} / \mathrm{kg})$ at a rate of $200-250 \mathrm{ml} / \mathrm{min}$, in addition to $300 \mathrm{ml}$ repeated every 10 to 15 minutes. In aortic valve surgery an extra half dose of cardioplegia was given directly into the coronary ostia. Patients were cooled down to $28-32^{\circ} \mathrm{C}$. Cold saline was used to cool surface of the heart. Valve annulus debridement of calcium was done usually in a blunt fashion. Patients were evaluated on an individual basis to determine if TCP is required. Patients who received PWs had ventricular wires on the anterior surface of the right ventricle. Atrial wires were additionally placed when AVB occurred after separation from CPB. After surgery all patients were transferred to $\mathrm{CICU}$ on mechanical ventilation. Continuous ECG monitoring was used in all patients. 12-lead ECG was performed for all patients upon CICU admission and daily till discharge from hospital.

\section{Statistical analysis}

Statistical analysis was carried out using Statistical Package for Social Sciences (SPSS, version 15). Descriptive statistics were obtained, such as mean values for continuous variables and proportions for categorical variables. The relationships between pacing and possible predictors were analyzed using Chi square test. Multiple logistic regression was used to determine the predictors of pacing in the multivariate analysis. Only factors that were shown to be significant predictors remained in the final regression model. A P-value $\leq 0.05$ was considered statistically significant.

\section{Results}

A total of 400 consecutive patients underwent valve surgery with ages ranging from 18 to 80 years with mean age (standard deviation- SD) of 51.81 (13.71) years. Group 1 consisted of 170 (42.5\%) patients with mean age (SD) of 44.25 (12.85) years. No patient in group1 required pacing by any means nor suffered any complication attributed to avoidance of PWs. Group 2 consisted of $230(57.5 \%)$ patients with mean age (SD) of 57.39 (11.49) years. Table 1 shows the characteristics of both groups with p-values. Among patients in group 2, only 55 (23.9\%) needed TCP (mean age $(\mathrm{SD})=62.27(10.87)$ years) and were compared with the remaining 175 (76.1\%) patients (mean age $(\mathrm{SD})=55.86$ (11.27) years) who did not need TCP. 12-lead ECG was used to diagnose conduction disturbances. The primary reasons for pacing included AVB of any degree in 25 (45.5\%) patients, nodal or junctional rhythms in 8 (14.6\%) patients, low cardiac output in $13(23.6 \%)$ patients, sinus bradycardia in $5(9.1 \%)$ patients, and asystole in $4(7.2 \%)$ patients. In no case were PWs used for diagnostic purposes, rapid atrial pacing, or left ventricular pacing. PWs were left in place for a minimum of 3 days. The mean (SD) duration of pacing was 
Table 1 Characteristics of total patients and by group according to demographic, preoperative, and intraoperative data ${ }^{\mathrm{a}}$

\begin{tabular}{|c|c|c|c|c|}
\hline Variable & $\frac{\text { Total }}{(n=400)}$ & $\frac{\text { Group } 1}{(n=170)}$ & $\frac{\text { Group } 2}{(n=230)}$ & p-value \\
\hline Age (year) & & & & $<0.005$ \\
\hline$<40$ & $78(19.5)$ & $62(79.5)$ & $16(20.5)$ & \\
\hline $40-59$ & $187(46.8)$ & $88(47.1)$ & 99 (52.9) & \\
\hline$\geq 60$ & $135(33.7)$ & $20(14.8)$ & $115(85.2)$ & \\
\hline Sex & & & & 0.141 \\
\hline Female & $177(44.3)$ & $68(38.4)$ & 109 (61.6) & \\
\hline Male & $223(55.7)$ & $102(45.7)$ & $121(54.3)$ & \\
\hline $\begin{array}{l}\text { Renal failure } \\
\text { (Creatinine } \geq 1.5 \mathrm{mg} / \mathrm{dl} \text { ) }\end{array}$ & $29(7.3)$ & $8(27.6)$ & $21(72.4)$ & 0.092 \\
\hline Diabetes mellitus & $80(20)$ & $19(23.7)$ & $61(76.3)$ & $<0.005$ \\
\hline COPD & $49(12.3)$ & $29(59.2)$ & $20(40.8)$ & 0.012 \\
\hline History of arrhythmia & $43(10.8)$ & $3(7)$ & $40(93)$ & $<0.005$ \\
\hline NYHA Class & & & & 0.027 \\
\hline $\mid-\|$ & $280(70)$ & $129(46.1)$ & $151(53.9)$ & \\
\hline$I I I-I V$ & $120(30)$ & $41(34.2)$ & $79(65.8)$ & \\
\hline $\begin{array}{l}\text { Left ventricle ejection } \\
\text { fraction (\%) }\end{array}$ & & & & 0.006 \\
\hline$>35$ & $259(64.5)$ & $123(47.5)$ & $136(52.5)$ & \\
\hline$\leq 35$ & $141(35.5)$ & $47(33.3)$ & $94(66.7)$ & \\
\hline PAP $(\mathrm{mmHg})$ & & & & 0.043 \\
\hline$<50$ & $360(90)$ & $159(44.2)$ & $201(55.8)$ & \\
\hline$\geq 50$ & $40(10)$ & $11(27.5)$ & $29(72.5)$ & \\
\hline Preoperative medications & & & & $<0.005$ \\
\hline Beta blockers & $107(26.8)$ & $45(42.1)$ & $62(57.9)$ & \\
\hline Digoxin & $42(10.5)$ & $19(55.2)$ & $23(54.8)$ & \\
\hline Amiodarone & $18(4.5)$ & $2(11.1)$ & $16(88.9)$ & \\
\hline Left atrium diameter ( $\mathrm{mm}$ ) & & & & 0.876 \\
\hline$<5.2$ & $347(86.7)$ & $148(42.7)$ & 199 (57.3) & \\
\hline$\geq 5.2$ & $53(13.3)$ & $22(41.5)$ & $31(58.5)$ & \\
\hline Type of surgery & & & & $<0.005$ \\
\hline Mitral valve & $140(35)$ & $80(57.1)$ & $60(42.9)$ & \\
\hline Aortic valve & 129(32.3) & $57(44.2)$ & $72(55.8)$ & \\
\hline Multiple valve & $73(18.2)$ & $21(28.8)$ & $52(71.2)$ & \\
\hline $\begin{array}{l}\text { Valve with coronary } \\
\text { artery bypass }\end{array}$ & $58(14.5)$ & $12(20.7)$ & $46(79.3)$ & \\
\hline Valve annulus calcification & $70(17.5)$ & $17(24.3)$ & $53(75.7)$ & $<0.005$ \\
\hline $\begin{array}{l}\text { Cardiopulmonary bypass } \\
\text { time (minute) }\end{array}$ & & & & $<0.005$ \\
\hline$<100$ & $317(79.3)$ & $157(49.5)$ & $160(50.5)$ & \\
\hline$\geq 100$ & $83(20.7)$ & $13(15.7)$ & $70(84.3)$ & \\
\hline
\end{tabular}

Table 1 Characteristics of total patients and by group according to demographic, preoperative, and intraoperative data ${ }^{a}$ (Continued)

Aorta cross clamp time

(minute)

$\begin{array}{llll}<60 & 318(79.5) & 160(50.3) & 158(49.7)\end{array}$

$\geq 60 \quad 82(20.5) \quad 10(12.2) \quad 72(87.8)$

$\begin{array}{lllll}\text { Intraoperative bradycardia } & 101(25.3) & 46(45.5) & 55(54.5) & 0.474\end{array}$

${ }^{a}$ Data are given as no. (\%).

$\mathrm{COPD}=$ chronic obstructive pulmonary disease $; \mathrm{NYHA}=$ New York Heart Association; $\mathrm{PAP}=$ pulmonary artery pressure; $\mathrm{PW}=$ temporary epicardial pacing wires.

53.12 (31.81) hours; the median was 12.5 hours. Only 5 (9.1\%) of the 55 patients who needed TCP, had implantation of permanent pacemaker, accounting for $1.25 \%$ of the cohort analyzed. The average time from surgery to implantation of permanent pacemaker was 65.33 hours.

Table 2 shows the univariate analysis of demographic, clinical, and preoperative characteristics of patients in group 2, in relation to TCP. The use of TCP differed significantly according to patients' age, diabetes mellitus, left ventricular ejection fraction (EF), New York Heart Association (NYHA) status, pulmonary artery pressure (PAP), and being on amiodarone. Patients on beta blockers were significantly less likely to need TCP.

Table 3 shows the univariate analysis of intraoperative variables in relation to TCP. When analyzed by type of surgery; $10 \%$ of patients who underwent mitral valve, $13.9 \%$ who underwent aortic valve, $34.8 \%$ who underwent valve with CABG, and $44.2 \%$ who underwent multiple valve surgeries needed TCP.

Table 4 shows the predictors of TCP in the multivariate analysis. Increased age by 1 year was associated with increased odds of TCP by $10 \%$. Those who underwent multiple valve surgery were significantly more likely to need TCP compared to patients who underwent single valve surgery.

\section{Discussion}

Historically, PWs have been routinely used after cardiac operations to optimize cardiac function and to suppress both atrial and ventricular tachyarrhythmias [4]. However, their use is not innocuous and associated with infrequent but lethal complications. Insertion can prolong the operative time and increase the risk of bleeding. Their extended use can result in failure of sensing or capturing [17]. During removal, patients are at risk of ventricular arrhythmias [18] and to a lesser extent bleeding due to injury of nearby structures [19-21]. Also retention of PWs may be complicated by deep seated infections or migration to different structures in the chest $[7-9,22,23]$. 
Table 2 Univariate analysis (group 2) for use of temporary pacing according to demographic, and preoperative variables $^{a}$

\begin{tabular}{|c|c|c|c|}
\hline \multirow[t]{2}{*}{ Variable } & \multicolumn{3}{|c|}{$\begin{array}{l}\text { Temporary } \\
\text { cardiac pacing }\end{array}$} \\
\hline & No & Yes & p-value \\
\hline Age (year) & & & 0.013 \\
\hline$<40$ & $13(81.3)$ & $3(18.8)$ & \\
\hline $40-59$ & $84(84.8)$ & $15(15.20)$ & \\
\hline$\geq 60$ & $78(67.8)$ & $37(32.2)$ & \\
\hline \multicolumn{4}{|l|}{ Sex } \\
\hline Female & $79(72.5)$ & $30(27.5)$ & 0.223 \\
\hline Male & $96(79.3)$ & $25(20.7)$ & \\
\hline Renal failure (creatinine > $1.5 \mathrm{mg} / \mathrm{dl}$ ) & & & 0.991 \\
\hline No & $159(76.1)$ & $50(23.9)$ & \\
\hline Yes & $16(76.2)$ & $5(23.8)$ & \\
\hline Diabetes mellitus & & & 0.001 \\
\hline No & $119(70.4)$ & $50(29.6)$ & \\
\hline Yes & $56(91.8)$ & $5(8.2)$ & \\
\hline COPD & & & 0.504 \\
\hline No & $161(76.7)$ & $49(23.3)$ & \\
\hline Yes & $14(70.0)$ & $6(30.0)$ & \\
\hline History of arrhythmia & & & 0.818 \\
\hline No & $144(75.8)$ & $46(24.2)$ & \\
\hline Yes & $31(77.5)$ & $9(22.5)$ & \\
\hline NYHA class & & & 0.000 \\
\hline$H-I I$ & $136(90.1)$ & $15(9.9)$ & \\
\hline III-IV & $39(49.4)$ & $40(50.6)$ & \\
\hline Left Ventricle ejection fraction (\%) & & & 0.001 \\
\hline$>35$ & $114(83.8)$ & $22(16.2)$ & \\
\hline$\leq 35$ & $61(64.9)$ & $33(35.1)$ & \\
\hline PAP $(\mathrm{mmHg})$ & & & 0.000 \\
\hline$<50$ & $171(85.1)$ & $30(14.9)$ & \\
\hline$\geq 50$ & $4(13.8)$ & $25(86.2)$ & \\
\hline Left atrium diameter (mm) & & & 0.104 \\
\hline$<5.2$ & $155(77.9)$ & $44(22.1)$ & \\
\hline$\geq 5.2$ & $20(64.5)$ & $11(35.5)$ & \\
\hline Beta blockers & & & 0.002 \\
\hline No & $119(70.8)$ & $49(29.2)$ & \\
\hline Yes & $56(90.3)$ & $6(9.70)$ & \\
\hline Digoxin & & & 0.440 \\
\hline No & $159(76.8)$ & $48(23.2)$ & \\
\hline Yes & $16(69.6)$ & $7(30.4)$ & \\
\hline Amiodarone & & & 0.011 \\
\hline No & $167(78.0)$ & $47(22.0)$ & \\
\hline Yes & $8(50.0)$ & $8(50.0)$ & \\
\hline
\end{tabular}

${ }^{\mathrm{a}}$ Data are given as no. (\%).

COPD $=$ chronic obstructive pulmonary disease; NYHA $=$ New York Heart

Association; PAP = pulmonary artery pressure.
Table 3 Univariate analysis (group 2) for use of temporary pacing according to procedure and intraoperative variables $^{\mathrm{a}}$

\begin{tabular}{|c|c|c|c|}
\hline \multirow[t]{2}{*}{ Variable } & \multicolumn{3}{|c|}{$\begin{array}{c}\text { Temporary } \\
\text { cardiac pacing }\end{array}$} \\
\hline & No & Yes & p-value \\
\hline Type of surgery & & & 0.000 \\
\hline Mitral valve & $54(90.0)$ & $6(10.0)$ & \\
\hline Aortic valve & $62(86.1)$ & $10(13.9)$ & \\
\hline Multiple valve & $29(55.8)$ & $23(44.2)$ & \\
\hline Valve with coronary artery bypass & $30(65.2)$ & $16(34.8)$ & \\
\hline Annulus Calcification & & & 0.000 \\
\hline No & $154(87.0)$ & $23(13.0)$ & \\
\hline Yes & $21(39.6)$ & $32(60.4)$ & \\
\hline Cardiopulmonary bypass time (minute) & & & 0.000 \\
\hline$<100$ & $140(87.5)$ & $20(12.5)$ & \\
\hline$\geq 100$ & $35(50.0)$ & $35(50.0)$ & \\
\hline Aorta cross clamp time (minute) & & & 0.000 \\
\hline$<60$ & $143(90.5)$ & $15(9.5)$ & \\
\hline$\geq 60$ & $32(44.4)$ & $40(55.6)$ & \\
\hline Bradycardia & & & 0.003 \\
\hline No & $125(71.4)$ & $50(28.6)$ & \\
\hline Yes & $50(90.9)$ & $5(9.1)$ & \\
\hline
\end{tabular}

During the last decade, routine insertion of PWs in CABG surgery, being on-pump or a beating heart, has been well studied and many centers turned to limit their use $[5,6,24]$. We already comply with these policies. In valvular and pediatric surgeries there is a historical evidence of routine use of PWs due to the increased risk of

Table 4 Multivariate analysis of factors associated with temporary cardiac pacing

\begin{tabular}{|c|c|c|c|}
\hline Variable & $\begin{array}{c}\text { Odds } \\
\text { ratio (OR) }\end{array}$ & $\begin{array}{l}95 \% \text { confidence } \\
\text { interval }(\mathrm{Cl})\end{array}$ & P-value \\
\hline Age & 1.1 & $(1.1,1.3)$ & 0.002 \\
\hline NYHA class (III- IV) & 5.6 & $(1.6,20.2)$ & 0.008 \\
\hline $\mathrm{PAP} \geq 50 \mathrm{mmHg}$ & 22.0 & $(3.4,142.7)$ & 0.001 \\
\hline Preoperative digoxin use & 8.0 & $(1.3,48.8)$ & 0.024 \\
\hline
\end{tabular}

Type of surgery

Mitral valve $\quad 1.0$

\begin{tabular}{lccc} 
Aortic valve & 2.2 & $(0.3,14.7)$ & 0.431 \\
$\quad$ Multiple valve & 13.5 & $(1.5,124.0)$ & 0.021 \\
$\begin{array}{l}\text { Valve with coronary artery } \\
\text { bypass }\end{array}$ & 3.6 & $(0.4,30.7)$ & 0.242 \\
$\begin{array}{l}\text { Aorta cross clamp time } \geq \\
\begin{array}{l}60 \text { min } \\
\text { Valve annulus calcification }\end{array}\end{array}$ & 7.8 & $(1.6,37.2)$ & 0.010 \\
\hline
\end{tabular}

NYHA = New York Heart Association; PAP = pulmonary artery pressure. 
AVB [12]. However, these recommendations are decades old and may not reflect modern surgical techniques and practice. Recent few reports studied the rate and the predictors of TCP after valvular and pediatric cardiac surgeries $[15,16,25]$. At our center, to avoid the above mentioned complications and in accordance with the published literature, and it is upon surgeon's discretion to safely select patients, we limited the insertion of PWs in valve surgery (usually based on; young age with minimal comorbidities, uncomplicated single valve surgery, not involving extensive decalcification, and after separation from $\mathrm{CPB}$ in sinus rhythm, and hemodynamically stable on minimal support, including recently, patients in sinus bradycardia who responds to minimal doses of beta-adrenergic drugs) (Table 1).

The need for TCP was mainly based on the presence of a mechanical injury to the conduction system caused by operative procedures in close physical proximity to the atrioventricular node or the His bundle, or an ischemic injury to the conduction system resulting during cardioplegic arrest, especially if associated with extensive coronary artery disease. Both mechanisms may evoke preexisting conduction defects or generate new ones.

In our study, only $23.9 \%$ of valve surgery patients with PWs insertion needed TCP which led us to reevaluate the use of PWs and to attempt to identify a subpopulation of valve patients for whom PWs are appropriate.

In the current series, patients who had PWs inserted were almost 10 years older than those who did not, and those more than 60 years old were, by both univariate and multivariate analysis, more likely to be paced.

Gender was not a predictor of TCP. This is consistent with other peer reviews $[15,26]$.

Data in the literature regarding the significance of chronic comorbidities such as chronic renal failure, chronic obstructive pulmonary disease, diabetes mellitus and preoperative arrhythmias as predictors of postoperative pacing are conflicting $[14,15,27]$. In our study none of the above mentioned comorbidities were significantly associated with the need for TCP in the multivariate analysis.

Advanced NYHA class was a predictor of TCP in both univariate and multivariate analysis. Pacing was used in patients with advanced NYHA class to improve cardiac output after separation from CPB to achieve hemodynamic stability. Also, most of them had severe left ventricular dysfunction with increased risk of developing various conduction disturbances [28]. This finding was supported by Gordon et al. [29]. On the contrary, advanced NYHA status was not a predictor of TCP by Ferrari et al. [15].

Increased PAP was an independent predictor of TCP by both univariate and multivariate analysis. Limongelli, et al. [30] reported pulmonary hypertension a risk factor for postoperative AVB following aortic valve surgery, as it acts on the right ventricular dimensions and shape, and interventricular septal thickness imposing progressive mechanical stretch that could affect the conduction system by altering the electrophysiological properties of its fibers.

Preoperative use of digoxin and beta-blockers are postulated as predictors of postoperative conduction disturbance $[14,31]$, especially of those with the block nature. In a recent study on patients after mitral valve surgery by Berdjas et al. [14], both digoxin and beta blockers, were found to significantly lower the risk of conduction disturbances. In our study, only digoxin was a predictor of TCP. Digoxin's primary mechanism of action is to increase the force of myocardial contractility in failing hearts by increasing the intracellular calcium concentration. However, its vagomimetic effect decreases sinoatrial and atrioventricular conduction and prolongs atrioventricular node refractory period, thus increasing the need for TCP [32]. Also digoxin has, even at therapeutic levels, an arrhythmogenic effect on ischemic hearts [33], which may include periods of prolonged crossclamping time.

Type of surgical procedure was a determinant of TCP. Patients who had multiple valve surgery and/or debridement of heavy annular calcification at the atrioventricular sinus area (the posterior commissure of the anterior mitral leaflet, the commissure between right- and noncoronary cusps of the aortic valve, and the septal leaflet of the tricuspid valve) were at an increased risk of physical injury to the atrioventricular node and conduction system and were significantly more likely to need TCP after separation from CPB. Although the need for pacing in combined valve and CABG surgery was more than in isolated single valve surgery, this difference did not reach statistical significance. This might be due to small sample size of this subgroup. In such patients it may be difficult to assure adequate and uniform delivery of the cardioplegic solution to protect the myocardium leading to new or further exacerbating existing conduction disturbances. These results coincide with other peer reviews [29,34].

Aortic crossclamp time more than 60 minutes, by both univariate and multivariate analysis, was a predictor of TCP. This is consistent with other peer reviews [35]. The occurrence of ischemic injury to the conduction system and the development of myocardial edema following prolonged periods of crossclamping might explain these findings.

In the interpretation of the study findings, we need to consider that this study is a retrospective analysis with a relatively limited number of patients done over a long time; however patients were followed prospectively during their hospitalization. Although a team of different surgeons performed the operations with different threshold for postoperative PWs insertion and pacing, all the patients were treated at a single center, and the 
operative methods remained substantially unchanged during the study.

\section{Conclusion}

Although limited by sample size, the present results suggest that routine use of PWs after valve surgery is necessary for high risk patients. Predictive factors of TCP after valve surgery were increased age, NYHA class (III-IV), $\mathrm{PAP} \geq 50 \mathrm{mmHg}$, digoxin use, complex surgical procedures (i.e. multiple valve surgery), heavy annular calcification, and crossclamp time $\geq 60 \mathrm{~min}$. Better patients selection, in addition to optimizing the medical condition through aggressive treatment of heart failure and pulmonary hypertension, shortening the cross clamping and $\mathrm{CPB}$ times, and careful debridement of calcified valve annulus, may lower the need for postoperative pacing in our practice. Prospective randomized well controlled studies on a larger number of patients, including quantitative assessment of valve annular calcium load and distribution, are necessary to draw solid conclusions on safely selected patients who do not require postoperative PWs insertion.

\section{Abbreviations}

PWs: Temporary epicardial pacing wires; CABG: Coronary artery bypass grafting; TCP: Temporary cardiac pacing; CICU: Cardiac intensive care unit; KAUH: King Abdullah University Hospital; AVB: Atrioventricular block; AF: Atrial fibrillation; ECG: Electrocardiogram; CPB: Cardiopulmonary bypass; SD: Standard deviation; EF: Left ventricular ejection fraction; NYHA: New York Heart Association; PAP: Pulmonary artery pressure.

\section{Competing interests}

The authors declare that they have neither financial nor non-financial competing interests.

\section{Authors' contribution}

NA participated in clinical practice, contributed to conception, design, acquisition of data, drafting the manuscript, and revising it critically for important intellectual content. KI participated in clinical practice, contributed to design, helped in drafting the manuscript, and revising it critically for important intellectual content. YK contributed to design, analysis and interpretation of data, and helped in drafting the manuscript. AA participated in clinical practice, helped in drafting the manuscript, and revising it critically for important intellectual content. All authors read and approved the final manuscript.

\section{Acknowledgments}

We would like to thank Dr. Motasem Abuelreish for his help in revising and editing the manuscript.

\section{Author details}

${ }^{1}$ Department of General Surgery, Jordan University of Science and Technology and King Abdullah University Hospital, Princess Muna Heart Center, Floor 8 C, Po Box 630001, Irbid 22110, Jordan. Department of Public Health, Community Medicine, and Family Medicine, Jordan University of Science and Technology and King Abdullah University Hospital, Po Box 630001, Irbid 22110, Jordan. ${ }^{3}$ Princess Muna Heart Center, Department of Anesthesia, Jordan University of Science and Technology and King Abdullah University Hospital, Po Box 630001, Irbid 22110, Jordan.

Received: 19 September 2013 Accepted: 5 February 2014 Published: 12 February 2014

\section{References}

1. Hodman RP, Starr A: Temporary post-operative epicardial pacing electrodes. Ann Thorc Surg 1969, 8:506-510.
2. Mills NL, Ochsner JL: Experience with atrial pacemaker wires implanted during cardiac surgery. J Thorac Cardiovasc Surg 1973, 66:878-886.

3. Hartzler GO, Maloney JD, Curtis JJ, Barnhorst DA: Hemodynamic benefits of atrioventricular sequential pacing after cardiac surgery. Am J Cardiol 1977, 40:232-236.

4. Archbold RA, Schilling RJ: Atrial pacing for the prevention of atrial fibrillation after coronary artery bypass graft surgery: a review of the literature. Heart 2004, 90:129-133.

5. Puskas JD, Sharoni E, Williams WH, Petersen R, Duke P, Guyton RA: Is routine use of temporary epicardial pacing wires necessary after either OPCAB or conventional CABG/CPB? Heart Surg Forum 2003, 6:E103-106.

6. Imren $\mathrm{Y}$, Benson AA, Oktar GL, Chema FH, Comas G, Naseem T: Is use of temporary pacing wire following coronary artery bypass surgery really necessary? J Cardiovasc Surg (Torino) 2008, 49:261-7.

7. Kapoor A, Syal S, Gupta N, Gupta A: Right paracardiac mass due to organized pericardial hematoma around retained epicardial pacing wires following aortic valve replacement. Interact CardioVasc Thorac Surg 2011, 13:104-6.

8. Horng GS, Ashley E, Balsam L, Reitz B, Zamanian RT: Progressive Dyspnea After CABG: Complication of retained epicardial pacing wires. Ann Thorac Surg 2008, 86:1352-1354.

9. Smith DE 3rd, DeAnda A Jr, Towe CW, Balsam LB: Retroaortic abscess: an unusual complication of a retained epicardial pacing wire. Interact Cardiovasc Thorac Surg 2013, 16:221-223.

10. Jackson M, Woods SS: Temporary transvenous and epicardial pacing. In Lynn-McHale Wiegand DJ, Carlson KK. Elsevier Saunders: AACN procedure manual for critical care. St. Louis; 2005:349-461.

11. Shamloo C: Epicardial pacing wire removal. In AACN procedure manual for critical care. Edited by Lynn-McHale Wiegand DJ, Carlson KK. St. Louis: Elsevier Saunders; 2005:311-313.

12. Waldo AL, MacLean WA, Cooper TB, Kouchoukos NT, Karp RB: Use of temporarily placed epicardial atrial wire electrodes for the diagnosis and treatment of cardiac arrhythmias following open-heart surgery. J Thorac Cardiovasc Surg 1978, 76:500-505.

13. Ceresnak SR, Pass RH, Starc TJ, Hordof AJ, Bonney WJ, Mosca RS, Liberman L: Predictors for hemodynamic improvement with temporary pacing after pediatric cardiac surgery. J Thorac Cardiovasc Surg 2011, 141:183-187.

14. Berdajs D, Schurr UP, Wagner A, Seifert B, Turina MI, Genoni M: Incidence and pathophysiology of atrioventricular block following mitral valve replacement and ring annuloplasty. Eur J Cardiothorac Surg 2008, 34:55-61.

15. Ferrari AD, Süssenbach CP, Guaragna JC, Piccoli Jda C, Gazzoni GF Ferreira DK, Albuquerque LC, Goldani MA: Atrioventricular block in the postoperative period of heart valve surgery: incidence, risk factors and hospital evolution. Rev Bras Cir Cardiovasc 2011, 26:364-372.

16. Gupta P, Jines P, Gossett JM, Maurille M, Hanley FL, Reddy VM, Miyake CY, Roth SJ: Predictors for use of temporary epicardial pacing wires after pediatric cardiac surgery. J Thorac Cardiovasc Surg 2012, 144:557-562.

17. Elmi F, Tullo NG, Khalighi K: Natural history and predictors of temporary epicardial pacemaker wire function in patients after open heart surgery. Cardiology 2002, 98:175-180.

18. Carroll KC, Reeves LM, Andersen G, Ray FM, Clopton PL, Shively M, Tarazi RY: Risks associated with removal of ventricular epicardial pacing wires after cardiac surgery. Am J Crit Care 1998, 7:444-449.

19. Del Nido P, Goldman BS: Temporary epicardial pacing after open heart surgery: complications and prevention. J Card Surg 1989, 4:99-103.

20. Price $C$, Keenan DJ: Injury to a saphenous vein graft during removal of a temporary epicardial pacing wire electrode. Br Heart J 1989, 61:546-547.

21. Matsushita T, Fuse H, Takeuchi K, Masuda S, Inoue T: Aortic bleeding One week after removal of an intraoperative epicardial temporary pacing wire. Ann Thorac Cardiovasc Surg 2013, 19:231-233.

22. Benson CC, Valentine AM, Economy KE, Hoffman-Sage $Y$, Bevilacqua LM, Podovei M, Opotowsky AR: Discovery and management of diaphragmatic hernia related to abandoned epicardial pacemaker wires in a pregnant women with $S, L, L$ transposition of the great arteries. Congenit Heart Dis 2012, 7:183-188.

23. Cohen SB, Bartz PJ, Earing MG, Sheil A, Nicolosi A, Woods RK: Myocardial infarction due to a retained epicardial pacing wire. Ann Thorac Surg 2012, 94:1724-1726

24. Asghar MI, Khan AA, lqbal A, Arshad A, Afridi: Placing epicardial pacing wires in isolated coronary artery bypass graft surgery: a procedure 
routinely done but rarely beneficial. J Ayub Med Coll Abbottabad 2009, 21:86-90.

25. Fishberger SB, Rossi AF, Bolivar JM, Lopez L, Hannan RL, Burke RP: Congenital cardiac surgery without routine placement of wires for temporary pacing. Cardiol Young 2008, 18:96-99.

26. Elahi MM, Darren L, Dhannapuneni RRV: Predictors of permanent pacemaker implantation during the early postoperative period after valve surgery. Tex Heart Inst J 2006, 33:455-457.

27. Bethea BT, Salazar JD, Grega MA, Doty JR, Fitton TP, Alejo DE, Borowicz LM $\mathrm{Jr}$, Gott VL, Sussman MS, Baumgartner WA: Determining the utility of temporary pacing wires after coronary artery bypass surgery. Ann Thorac Surg 2005, 79:104-107.

28. Linde C, Daubert C: Cardiac resynchronization therapy in patients with New York Heart Association class I and II heart failure: an approach to 2010. Circulation 2010, 122:1037-1043.

29. Gordon RS, Cohen G, Joan I, Gideon C, Ralph-Edwards AL: Permanent cardiac pacing after a cardiac operation: Predicting the use of permanent pacemakers. Ann Thorac Surg 1998, 66:1698-1704.

30. Limongelli G, Ducceschi V, D'Andrea A, Renzulli A, Sarubbi B, De Feo M, Cerasuolo F, Calabrò R, Cotrufo M: Risk factors for pacemaker implantation following aortic valve replacement: a single center experience. Heart 2003, 89:901-904.

31. Jokinen JJ, Mustonen PK, Hippelainen MJ, Rehnberg LS, Hartikainen JE: Effects of coronary artery bypass related conduction defects: a 10-year follow-up study. Scand Cardiovasc J 2004, 38:235-239.

32. Krum H, Bigger JT Jr, Goldsmith RL, Packer M: Effect of long-term digoxin therapy on autonomic function in patients with chronic heart failure. J Am Coll Cardiol 1995, 25:289-294.

33. Lown B, Graboys TB, Podrid PJ, Cohen BH, Stockman MB, Gaughan CE: Effect of a digitalis drug on ventricular premature beats. N Engl J Med 1977, 296:301-306.

34. Erdogan HB, Kayalar N, Ardal H, Omeroglu SN, Kirali K, Guler M, Akinci E, Yakut C: Risk factors for requirement of permanent pacemaker implantation after aortic valve replacement. J Card Surg 2006, 21:211-215.

35. Schurr UP, Berli J, Berdajs D, Häusler A, Dzemali O, Emmert M, et al: Incidence and risk factors for pacemaker implantation following aortic valve replacement. Interact Cardiovasc Thorac Surg 2010, 11:556-560.

doi:10.1186/1749-8090-9-33

Cite this article as: AlWaqfi et al:: Predictors of temporary epicardial pacing wires use after valve surgery. Journal of Cardiothoracic Surgery 2014 9:33.

\section{Submit your next manuscript to BioMed Central and take full advantage of:}

- Convenient online submission

- Thorough peer review

- No space constraints or color figure charges

- Immediate publication on acceptance

- Inclusion in PubMed, CAS, Scopus and Google Scholar

- Research which is freely available for redistribution 